\section{Estudo \\ cobebate}

em Testã⿻

Planejamento
Revista Estudo \& Debate, Lajeado, v. 25, n. 2, 2018. ISSN 1983-036X

DOI: http://dx.doi.org/10.22410/issn.1983-036X.v25i2a2018.1443

\title{
DESIGUALDADE DE OPORTUNIDADES: UMA ANÁLISE DA REGIÁO METROPOLITANA DE PORTO ALEGRE AO LONGO DA DÉCADA DE 2000 ${ }^{1}$
}

\author{
Bianca dos Santos de Lima², Izete Pengo Bagolin ${ }^{3}$
}

Resumo: O objetivo do artigo é analisar o acesso e a distribuição das oportunidades humanas na Região Metropolitana de Porto Alegre entre 2000 e 2010 através da utilização da metodologia de Barros et al (2009). A desigualdade individual da renda, resultado da interação entre fatores de esforço e circunstância pode ser mensurada por meio do acesso aos serviços básicos. Os resultados mostram redução no índice de oportunidades humanas, evidenciando um pequeno aumento da desigualdade no acesso a tais serviços.

Palavras-chave: Oportunidades Humanas. Desigualdade. Renda.

\section{INEQUALITY OF OPPORTUNITIES: NA ANALYSIS OF THE METROPOLITAN REGION OF PORTO ALEGRE FROM 2000 TO 2010}

\begin{abstract}
The objective of this study is to analyze the access and the distribution of human opportunities in the Metropolitan Region of Porto Alegre between 2000 and 2010 using Barros`s et al (2009) methodology. Individual income inequality which is the a result of the interaction between factors of effort and circumstance, can be measured through access to basic services. The results show a reduction in the index of human opportunities, showing a small increase in inequality in access to such services.
\end{abstract}

Keywords: Human Opportunity. Inequality. Income.

\section{INTRODUÇÁO}

Ao longo do período de 2000 a 2010, houve redução da desigualdade de renda na Região Metropolitana de Porto Alegre (RMPA). Com base nos microdados do Censo

1 Texto inicial apresentado e publicado em: LIMA, Bianca dos Santos de; BAGOLIN, Izete Pengo. Desigualdade de oportunidades: Uma análise da região Metropolitana de Porto Alegre ao longo da década de 2000. In: ENCONTRO DE ECONOMIA DA REGIÃO SUL, 19., 2016, Florianópolis-SC. Anais... Florianópolis-SC, ANPEC/SUL, 2016.

2 Economista pela PUCRS. E-mail: bianca.oirs@gmail.com

3 Economista. Professora do Programa de Pós-Graduação em Economia da PUCRS. E-mail: izete.bagoln@pucrs.br 
(IBGE, 2015) é possível verificar que o Índice de Gini que em 2000 era de 0,5929 passou em 2010 para 0,5768 .

De acordo com a abordagem de Romer (1998) as diferenças de renda entre os adultos devem-se a dois elementos, sendo eles o esforço e as circunstâncias individuais. A desigualdade proveniente do esforço é considerada justa, pois o resultado obtido de cada indivíduo depende somente de fatores de sua responsabilidade. No entanto, é considerada injusta a desigualdade de renda originada das circunstâncias, tais como raça, sexo, local de nascimento, grau de instrução dos pais, etc. Estes são considerados fatores de não responsabilidade das pessoas, dado que estas circunstâncias fogem do controle dos agentes, e por tanto, esta desigualdade deveria ser neutralizada.

As circunstâncias podem facilitar ou dificultar o acesso aos serviços considerados essenciais para uma vida produtiva, como água potável, saneamento, eletricidade e educação básica. Ou seja, o conjunto das variáveis de não responsabilidade dos indivíduos seria responsável por determinar as oportunidades que os indivíduos possuiriam acesso.

A literatura assume que a formação das regiôes metropolitanas tem como objetivo promover o desenvolvimento econômico em uma maior escala do que a esfera municipal. Percebe-se que isso ocorre na RMPA, pois é considerado um importante centro econômico do Rio Grande do Sul, representando em média 40\% do PIB do estado (ALONSO E BRINCO, 2009; MARTINS, 2013). Verifica-se a importância de analisar esta região, pois, mesmo havendo melhora no índice de Gini, conforme já citado, não basta considerar somente a renda como um parâmetro de bem-estar, mas deve-se também levar em conta à distribuição do acesso às oportunidades básicas.

Apoiado na perspectiva das desigualdades sociais e na busca por contribuir com os estudos sobre as desigualdades de oportunidades, o presente trabalho utiliza a metodologia proposta por Barros et al. (2009). Tem como principal objetivo a mensuração da distribuição do acesso às oportunidades humanas básicas entre os municípios da RMPA.

Para tal propósito, foi construído o Índice de Oportunidade Humana $(\mathrm{IOH}) \mathrm{da}$ população com idade entre seis e quinze anos da RMPA. Para a elaboração deste índice foram utilizados os microdados do Censo 2000 e 2010, disponibilizados pelo Instituto Brasileiro de Geografia e Estatística (IBGE). Nesse estudo o acesso a água canalizada, saneamento, energia elétrica e educação foram as oportunidades básicas possíveis de serem calculadas e consideradas importantes para garantir o desenvolvimento humano e o progresso das crianças. A escolha destas variáveis esta ancorada em Barros et al 2009 e limitadas pelas informaçôes disponíveis nos censos. Para o autor, informaçôes sobre vacinação das crianças, por exemplo, são importantes. No entanto, essa informação não está disponível nos microdadados do censo.

O trabalho é organizado em cinco seções, incluindo esta introdução. A seção dois é revisado do contexto histórico das desigualdades no Brasil, e definido o conceito de oportunidade humana, bem como sua origem e forma de mensuração. A partir disto, na seção três serão abordadas as características da RMPA e a sua importância para o estado do Rio Grande do Sul. A seção quatro constitui-se na exposição da metodologia utilizada para o cálculo do $\mathrm{IOH}$, e no tratamento que será realizado na base de dados do IBGE. Nesta seção 
serão investigados os resultados da distribuição das oportunidades e a sua relação com as variáveis de circunstância obtidos por meio de regressão logística. Por fim, são apresentadas as considerações finais do trabalho.

\section{OPORTUNIDADE HUMANA}

\subsection{As desigualdades no Brasil}

Os problemas sociais enfrentados principalmente nos países em desenvolvimento podem ser compreendidos por diversos tipos de desigualdades, desde desigualdade de renda, de gênero, de escolaridade, de raça, etc., até desigualdade de oportunidade.

Conforme destacado por Paes de Barros, Foguel e Ulyssea (2006) as investigações em torno dos problemas sociais e da distribuição de renda estão entre os temas mais discutidos da literatura econômica no Brasil como em outros países. Mas, quando se estuda o caso do Brasil, nota-se uma alta concentração de renda desde o início de sua história. Esta concentração de renda sempre foi uma variável preocupante na sociedade brasileira, pois desde o período da colonização, apenas uma pequena parte da população concentra a maior parcela da renda.

Com base no cenário em que ainda há concentração de renda no país, surgem por parte dos pesquisadores especializados alguns questionamentos sobre qual a origem e as possíveis causas dessa desigualdade. As explicaçóes e os estudos são diversos, mas, a partir da constatação do alto nível de desigualdade de oportunidade no Brasil, verificado no estudo realizado por Bourguignon et al (2007) e posteriormente confirmado em outras aplicaçóes da abordagem para o Brasil (FIGUEIREDO et al., 2012, ; FIGUEIREDO E REGO, 2012; CAVALCANTI E RAMOS, 2013), fica evidente que ainda persistem questionamentos importantes a serem investigados.

Levando em consideração que a desigualdade de renda é fortemente ligada às oportunidades, Souza (2009) destaca que a concorrência por recursos escassos começa antes do início da fase escolar de cada indivíduo e está predeterminada principalmente nas relações internas familiares. Desta maneira, a competição por estes recursos demonstra que as crianças chegam à escola em condições não equivalentes, ou seja, não admitir que exista essa desigualdade é seguir supondo que todas as pessoas nascem com as mesmas habilidades e oportunidades.

$\mathrm{Na}$ prática, inúmeras das oportunidades das crianças brasileiras não são apenas limitadas às suas escolhas, e tampouco relacionadas ao esforço e/ou capacidade desprendida ao longo de suas atividades produtivas, mas sim às particularidades envolvidas no nascimento. Ou seja, parte considerável da desigualdade vivenciada pode ser explicada por circunstâncias além do controle do indivíduo em razão da não distribuição equitativa de definidas oportunidades básicas para todas as crianças (JESUS FILHO et al., 2014).

Em suma, as questóes sobre as desigualdades, sejam elas de renda ou de oportunidade, apresentam algumas respostas quanto aos questionamentos sobre as causas das desigualdades sociais que hoje ainda se observam no país. 


\subsection{A oportunidade humana, origem, conceito e formas de mensuraçáa}

Apesar da da renda ainda ser a principal variável utilizada para mensurarr o crescimento e o desenvolvimento de uma sociedade, tem sido crescente o número de trabalho que buscam analisar outros aspectos, como as oportunidades humanas, as quais podem ser a explicaçáo para a existente desigualdade na sociedade. Alguns teóricos relacionam a renda com a composição do ambiente dos indivíduos para definir o resultado do desempenho destes ao longo da vida (BARROS ET AL, 2009; CAVALCANTI E RAMOS, 2013,FIGUEIREDO, SILVA E REGO, 2012).

O conceito de oportunidade surgiu através dos trabalhos desenvolvidos por Roemer (1998), que fundamenta sua teoria através da concepção de John Rawls . Para Roemer (1998), a definição do conceito de oportunidade pode ser observada através dos efeitos alcançados pelos indivíduos, e é expressa em dois principais elementos: (I) o esforço desempenhado por estes e (II) as circunstâncias em que estão inseridos, ou seja, suas particularidades inatas, como gênero, raça, background familiar. Considera-se o esforço como um fator de responsabilidade, e as circunstâncias como um fator de não responsabilidade. Logo, tais circunstâncias seriam responsáveis por definir as oportunidades a que os indivíduos desfrutariam de acesso.

No entanto deve-se destacar que, para Roemer (1998), os dois principais elementos estariam relacionados a duas formas diferentes de desigualdade de renda, as consideradas justas (esforço) e injustas (circunstância). A primeira é o resultado do esforço de cada indivíduo, ou seja, a ideia é que cada um terá a sua renda proporcional ao seu desempenho, se um se dedica mais que outro entấo esse indivíduo receberá mais, e essa desigualdade de renda é considerada justa. Já as desigualdades injustas seriam oriundas dos fatores que fogem do controle dos agentes, que independem do esforço desempenhado e, portanto, deveriam ser neutralizados. Desta maneira, a consequência da desigualdade de renda é a relação entre as circunstâncias e o esforço, mas o importante a ser destacado não é a desigualdade de renda e sim a de oportunidade.

De modo geral, a abordagem constituída nas oportunidades indica que uma sociedade justa não é aquela em que a igualdade de resultado é necessariamente igual, mas sim aquela em que há plena igualdade de acesso aos bens e serviços básicos fundamentais para o desenvolvimento de cada indivíduo.

$\mathrm{Na}$ busca por identificar como está o acesso à cobertura dos serviços básicos, Barros et al. (2009) desenvolveram um índice para mensurar a desigualdade de oportunidades que afeta o bem-estar dos indivíduos. Este foi elaborado também com o intuito de arquitetar políticas públicas de longo prazo e descontinuar os ciclos geracionais de desigualdade. Este índice é fundamentado no uso de circunstâncias exógenas que influenciam o acesso dos

4 Na concepção de Rawls (1971), uma sociedade só poderia ser considerada justa se houvesse igualdade na atribuição de deveres e direitos básicos, desta forma, proporcionaria liberdade a todos (princípio da igual liberdade). $\mathrm{O}$ autor também define que as desigualdades econômicas e sociais deveriam estar ordenadas de tal maneira que seriam consideradas como vantajosas para todos, resultando em benefícios para os indivíduos menos favorecidos (princípio da diferença). Apesar disso, a elaboração teórica do autor não traz claramente a definição de oportunidade. 
indivíduos a bens e serviços elementares ao seu bem-estar, e no grau em que elas não podem vir a ser responsabilizadas por elementos fora de seu controle. O Banco Mundial utiliza o índice para medir o quão equitativo está o acesso a bens e serviços básicos para os países da América Latina e do Caribe.

Consideram-se relevantes as oportunidades para a definição dos resultados obtidos pelos indivíduos. Barros et al. (2009), ao desenvolverem o Índice de Oportunidade Humana $(\mathrm{IOH})$, utilizam uma medida sucinta, que salienta o quão distante está o indivíduo do acesso pleno e igualitário a bens ou serviços básicos de uma determinada localidade. Tal abordagem enfatiza a utilização apenas de variáveis de circunstância, as quais são consideradas fatores de não responsabilidade e possuem o intuito de evidenciar como as características individuais influenciam a probabilidade de acesso às oportunidades básicas.

Para sua elaboração, os autores estabelecem a aplicação unicamente de indivíduos na faixa etária entre zero e dezesseis anos. Este corte etário é explicado por dois motivos principais: (I) Pessoas nessa faixa etária ainda estão se capacitando, e possíveis desigualdades de oportunidades devem-se às suas características pessoais e não ao seu esforço; e (II) há comprovaçóes de que políticas públicas focadas no início do ciclo de vida são menos custosas e mais eficazes. Desta maneira, obtêm-se unicamente os resultados do componente de circunstância.

Conforme estruturado por Barros et al. (2009), o IOH propóe um modelo de mensuração de desigualdade de oportunidade, em vista do avanço de bem-estar econômico, sendo este constituído de um conjunto de oportunidades de serviços básicos considerados necessários, tais como: o acesso à água canalizada, energia elétrica, saneamento adequado e educação básica. As particularidades referentes à habitação são utilizadas como parâmetros das características da vida dos indivíduos, e a perspectiva de estar na série certa e em idade compatível evidencia o acesso à educação básica.

$\mathrm{O} \mathrm{IOH}$ é formado por um elemento de cobertura de acesso a determinado bem ou serviço básico, e também pela dissimilaridade que tem por objetivo mensurar a desigualdade de oportunidade de acordo com as características pessoais. $\mathrm{O}$ valor do índice varia entre 0 e 1 , sendo que $\mathrm{IOH}=1$ representa igualdade de oportunidade e completa cobertura de serviços.

\section{IMPORTÂNCIA E CARACTERÍSTICAS DA REGIÁO METROPOLITANA DE PORTO ALEGRE}

Conforme explica Catalão (2009), na procura por solucionar muitos dos problemas urbanos que seriam comuns entre as cidades aglomeradas, e que estavam além da esfera dos municípios, foram criadas as regióes metropolitanas brasileiras. Além disto, observase a necessidade de promover o desenvolvimento socioeconômico em uma escala regional em que houvesse uma ação conjunta no planejamento e na gestão dos bens e serviços metropolitanos.

Conforme a Constituição brasileira, as regióes metropolitanas são formadas por municípios de uma mesma comunidade socioeconômica que tenham por objetivo realizar serviços públicos de interesse comum. A Lei Complementar Federal 14 de 08/06/1973 
instituiu formalmente a RMPA, sendo esta integrada por 14 municípios $^{5}$, entre estes, Porto Alegre, que é a capital do Rio Grande do Sul e também a cidade mais antiga.

A RMPA está localizada na zona nordeste do estado do Rio Grande do Sul, possuindo atualmente uma extensão territorial de $10.345,45 \mathrm{Km}^{2}$, o que equivale a $3,67 \%$ da dimensão total do Estado $^{6}$. Desde a sua instituição até os dias de hoje, houve processos de desmembramento, emancipação e incorporação de novos municípios, o que resultou em uma nova formação da região, sendo esta constituída atualmente por 34 municípios ${ }^{7}$. A expectativa dos municípios é que, ao serem incluídos na RMPA, estes façam parte de projetos governamentais exclusivos para este tipo de região (MARTINS, 2013).

Conforme os dados divulgados pela Fundação de Economia e Estatística (FEE), o PIB da RMPA em 2012 representava 44,39\% do PIB do estado do Rio Grande do Sul. Na composição do PIB da RMPA, Porto Alegre representava neste mesmo ano 38,40\% do produto. Já o PIB per capita da RMPA em 2012 era de R $\$ 28.845$, número este superior ao do estado, que era de R\$24.563 no mesmo período.

Em 2010 é possível observar que, na estrutura do Valor Agregado Bruto (VAB), os serviços representavam a maior participação na RMPA, 66,92\%, seguidos da indústria, com participação de $32,38 \%$, e da agricultura, com apenas $0,70 \%$. O VAB da região representava $43,27 \%$ do VAB total do estado (MARTINS, 2013).

Segundo Alonso e Brinco (2009), a parte norte da RMPA é composta por 12 munícipios $^{8}$ que formam o Vale dos Sinos. Observando esta regiáo, fica evidente que em Novo Hamburgo e São Leopoldo é muito intenso o setor coureiro-calçadista, bem como os segmentos afins. Estes dois municípios representam polos de comércio e de serviço nesta região.

A parte sul da região metropolitana também é composta por 12 municípios ${ }^{9}$, sendo Porto Alegre um deles. Uma característica marcante desta região é a diversificação dos setores atuantes e o fornecimento de produtos de maior valor agregado. Nesta região existe uma alta dinâmica nos setores secundários e terciários. Entretanto, de leste a oeste da RMPA,

5 Alvorada, Cachoeirinha, Campo Bom, Canoas, Estância Velha, Esteio, Gravataí, Guaíba, Novo Hamburgo, Porto Alegre, São Leopoldo, Sapiranga, Sapucaia do Sul e Viamão.

6 Conforme dados do IBGE o estado do Rio Grande do Sul possui uma área de 281.748,538 km².

7 Porto Alegre, Alvorada, Araricá, Arroio dos Ratos, Cachoeirinha, Campo Bom, Canoas, Capela de Santana, Charqueadas, Dois Irmãos, Eldorado do Sul, Estância Velha, Esteio, Glorinha, Gravataí, Guaíba, Ivoti, Igrejinha, Montenegro, Nova Hartz, Nova Santa Rita, Novo Hamburgo, Parobé, Portáo, Rolante, Santo Antônio da Patrulha, São Jerônimo, São Leopoldo, São Sebastiáo do Caí, Sapiranga, Sapucaia do Sul, Taquara, Triunfo e Viamão.

8 Campo Bom, Dois Irmãos, Sapiranga, Nova Hartz, Araricá, Parobé, Taquara, Ivoti, Estância Velha e Portão são os demais integrantes do norte da RMPA.

9 Canoas, Esteio, Sapucaia do Sul, Nova Santa Rita, Cachoeirinha, Alvorada, Gravataí, Glorinha, Viamão, Eldorado do Sul e Guaíba são os demais municípios do sul da RMPA. 
encontram-se municípios que são mais rurais e que compóem há menos tempo a região metropolitana.

Com base no Índice de Desenvolvimento Humano Municipal (IDHM) ${ }^{10}$, em 2010 o nível de desenvolvimento em geral dos 34 municípios da RMPA encontrava-se na faixa entre 0,661 a 0,805 . Porto Alegre foi o município que apresentou o melhor resultado no índice, ficando com 0,805, número este superior ao do estado do Rio Grande do Sul, que foi de 0,746 .

A FEE é responsável por divulgar os dados do Índice de Desenvolvimento Econômico (Idese) ${ }^{11}$ dos municípios do Rio Grande do Sul, e o resultado apresentado em 2012 para a RMPA foi de 0,744. Entre as três variáveis analisadas no indicador, a saúde foi a que apresentou melhores resultados, ficando com 0,804 , seguida pela renda, com 0,745 , e pela educação, com 0,685 .

Conforme os dados do Censo do IBGE, em 2010 a população da RMPA representava $37,70 \%$ do total de habitantes do estado do Rio Grande do Sul. O município de Porto Alegre era de 1,409 milhóes, número este que demonstrava uma concentração de 34,95\% da população da RMPA, sendo o único município com mais de um milhão de habitantes.

No período de 2000-2010 observou-se que a região metropolitana obteve uma taxa de crescimento populacional de $0,71 \%$, número este que foi menor em relação ao período de 1991-2000, em que a taxa era de 1,59\%.

Quando comparados os resultados do Censo de 2000 e 2010, é possível notas o aumento da população mais idosa ${ }^{12}$, e consequentemente a redução da população mais jovem. Mas, conforme destacado por Barcelos e Jardim (2015), o aumento da população potencialmente ativa gera resultados positivos na perspectiva do desenvolvimento econômico, pois, com um número maior da população em idade para trabalhar, podese ampliar a produção. Ainda compreendem que, mesmo havendo uma diminuição da população mais jovem, também seria benéfico para a regiáo pois diminuiria a pressão por educação básica.

\section{PROCEDIMENTOS METODOLÓGICOS}

\subsection{Base de dados}

A base de dados é composta pelos dados do Instituto Brasileiro de Geografia e Estatística (IBGE), referentes ao Censo dos anos de 2000 e 2010. A escolha deste período

10 O Índice de Desenvolvimento Humano (IDH) é uma medida resumida do progresso a longo prazo em três dimensões básicas do desenvolvimento humano: renda, educação e saúde.

11 O Idese é um índice que mensura e acompanha o nível de desenvolvimento do estado do RS. Abrange um conjunto de três blocos temáticos: educação, renda e saúde.

12 Conforme Lei Estadual 10.741 de 01/10/2003, são consideradas idosas as pessoas com idade igual ou superior a 60 anos. 
deve-se ao fato de 2010 representar os dados mais recentes até então publicados pelo IBGE, enquanto que a utilização dos dados de 2000 permite capturar as modificaçóes ocorridas ao longo de 10 anos, tempo este em que se acredita ser possível encontrar alteraçóes significativas no acesso a um conjunto de bens e serviços básicos (CAVALCANTI; RAMOS, 2013).

Para excluir o fator esforço e analisar apenas fatores circunstanciais, adotaram-se como unidade de observaçáo pessoas de 6 a 15 anos de idade, e as variáveis utilizadas neste estudo seguem a classificação em conformidade com a metodologia apresentada Barros et al. (2009), e são descritas a seguir.

O conjunto de oportunidades em análise são o acesso à água canalizada, energia elétrica, saneamento adequado e educação básica. Para medir o saneamento adequado, utilizou-se a definição do IBGE de cobertura de esgotamento sanitário, considerando da seguinte maneira: (i) rede coletora de esgoto ou pluvial; (ii) fossa séptica liga à rede coletora de esgoto ou pluvial ou (iii) fossa séptica não ligada à rede coletora de esgoto ou pluvial. Para medir o acesso à educação básica, observou-se se os indivíduos estavam frequentando escola/creche e se estavam em idade escolar adequada ${ }^{13}$.

As oportunidades apresentadas foram identificadas de maneira binária, utilizando o valor de 1 se o indivíduo possui acesso a determinado bem ou serviço, e 0 se não possui acesso.

As variáveis de circunstância ${ }^{14}$ escolhidas para serem utilizadas como regressores do conjunto de oportunidades são: gênero (sexo) e raça (cor), os quais tem o objetivo de identificar a existência de discriminação direta; renda mensal domiciliar per capita, para captar os efeitos provenientes de recursos a que os indivíduos possuem acesso; área de residência, para analisar disparidades entre o meio urbano e rural; e o número de pessoas que vivem no domicílio, para avaliar a estrutura familiar (FERREIRA et al., 2012). No Quadro 1 encontram-se as variáveis escolhidas para este estudo.

13 Para a variável idade escolar adequada, adotou-se a divisão do Conselho Nacional de Educação, diferenciando o ano de 2012 devido a lei ${ }^{\circ} 11.274$, de 06 de fevereiro de 2006, em que estabelece a inclusáo do nono ano no Ensino Fundamental. Vale salientar que para esta variável, o corte etário é de 6 a 16 anos (CAVALCANTI; RAMOS; 2013, p. 7)

14 Apesar da presença da mãe e dos anos de estudo da pessoa de referência representar um importante fator de circunstância, conforme demonstrado no estudo de Barros et al. (2009), devido a insuficiência de dados no Censo de 2000 fez com que, no presente trabalho, não fossem consideradas. 
Quadro 1 - Lista de variáveis

\begin{tabular}{|c|c|c|}
\hline Tipo & Variável & Especificação \\
\hline \multirow{5}{*}{$\begin{array}{l}\text { Variável de } \\
\text { oportunidade } \\
\text { (Op) }\end{array}$} & Água canalizada & \multirow{4}{*}{$\begin{array}{l}\mathrm{Op}=1 \text { se tem acesso } \\
\mathrm{Op}=0 \text { se não tem acesso }\end{array}$} \\
\hline & Saneamento & \\
\hline & Eletricidade & \\
\hline & Escola & \\
\hline & Idade escolar adequada & $\begin{array}{l}\text { Op }=1 \text { está na idade certa; } \mathrm{Op}=0 \text { não está na idade } \\
\text { certa }\end{array}$ \\
\hline \multirow{5}{*}{$\begin{array}{l}\text { Variável } \\
\text { circunstância } \\
\text { (Cc) }\end{array}$} & Gênero (sexo) & $\mathrm{Cc}=1$ se é masculino; $\mathrm{Cc}=0$ se é feminino \\
\hline & Raça (cor) & $\mathrm{Cc}=1$ se é branco; $\mathrm{Cc}=0$ se é não é branco \\
\hline & Área & $\mathrm{Cc}=1$ se reside no urbano; $\mathrm{C} c=0$ se reside no rural \\
\hline & Número de pessoas & $\mathrm{Cc}=$ contínua \\
\hline & Renda per capita & $\mathrm{C} c=$ contínua, logarítmica \\
\hline
\end{tabular}

Fonte: Cavalcanti e Ramos (2013, p.7)

A seleção dos dados foi realizada de acordo com os municípios que formam a RMPA, esta que foi estudada e analisada ao longo deste trabalho, bem como o corte etário proposto. Foram excluídos também os indivíduos com valores nulos nas variáveis de interesse do presente estudo. Logo, a amostra resultou em 116.266 observaçôes.

\section{2 Índice de Desigualdade de Oportunidades}

Para o cálculo do índice de desigualdade de oportunidades para a RMPA, foi utilizada a metodologia criada por Barros et al. (2009) e já adotada por outros autores na realização de trabalhos que mensuraram a distribuição das oportunidades. Por exemplo, Ferreira et al. (2012) realizarem uma análise espacial para os municípios brasileiros a partir do Censo 2010. Essa metodologia, apesar de relativamente simples, permite mensurar a cobertura e a distribuição daquelas oportunidades consideradas mais básicas. No presente estudo, estas oportunidades básicas são o acesso à água canalizada, energia elétrica, saneamento adequado e educação básica. $\mathrm{O}$ índice de desigualdade de oportunidade possuiu dois componentes que são (1) a taxa de cobertura (TC) de uma dada oportunidade básica e (2) a equidade na distribuição das oportunidades.

A taxa de cobertura é de fácil obtenção a partir dos microdados da amostra do censo. Para isso, baseando-se no resultado individual da amostra de tamanho N, consegue-se calcular a taxa de cobertura (TC) do serviço em análise, ou seja, mede-se a proporção do acesso ao serviço $j$ pela pessoa $i$. A taxa cobertura contribui de maneira positiva para o aumento do $\mathrm{IOH}$, e seu resultado admite valores no intervalo entre 0 e 1 , em que, quanto mais próximo de 0 , significa menor cobertura ao prover determinado bem. Para tal, calculase a média aritmética das probabilidades condicionais individuais, expressa por:

$$
T C=\frac{1}{N} \sum_{i=1}^{n} p_{i}
$$


Sendo que a probabilidade de uma criança $i$ ter acesso $(A=1)$ a determinado bem ou serviço, condicionado ao seu vetor de variáveis de circunstâncias $(x)$, pode ser expressa por:

$$
P\left(A=1 \mid x_{1 i} \ldots x_{m i}\right)
$$

em que $i=1, \ldots, n$ e $\left\{x_{k} \mid k=1, \ldots, m\right\}$.

Por meio do modelo de regressão logística, é possível determinar a relação entre o conjunto de circunstâncias e o seu acesso. Dado que este está limitado às características individuais e ao ambiente, estimam-se assim:

$$
p_{i}=\frac{\exp \left(\beta_{0}+\sum_{k=1}^{m} \beta_{k} x_{k i}\right)}{1+\exp \left(\beta_{0}+\sum_{k=1}^{m} \beta_{k} x_{k i}\right)}
$$

sendo $p_{i}$ a probabilidade individual.

Salienta-se, porém, que mesmo sendo um indicador significativo para evidenciar a disponibilidade de oportunidades básicas, a taxa de cobertura não leva em consideração como o acesso a estes bens e serviços estáo distribuídos entre os grupos definidos pelas circunstâncias. Desse modo, Barros et al (2009) apresentam o índice de dissimilaridade (ID), que tem por finalidade mensurar a fraçáo de todas as oportunidades que necessitam ser reposicionadas para que a igualdade de oportunidade seja conservada. Ela é dada por:

$$
I D=\frac{1}{2 T C} \sum_{i=1}^{n} \frac{1}{N}\left|p_{i}-T C\right|
$$

O índice de dissimilaridade resulta em valores entre 0 e 1 , sendo que, quanto mais próximo de 1, mais desigual é a distribuição de determinada oportunidade. Sendo assim, 1 - ID remete à parcela alocada igualitariamente entre os indivíduos.

Uma vez calculado índice de dissimilaridade e a taxa de cobertura, obtém-se o IOH, pois este é resultado da combinaçáo entre estes dois elementos, e pode ser representado por:

$$
I O H=T C *(1-I D)
$$

Neste caso a taxa de cobertura atua como fator de ponderação, sendo alocada conforme o princípio de igualdade de oportunidade $(1-D)$. Ao certificar-se de que o acesso dos indivíduos a determinada oportunidade é isento da transmissão de variáveis de não responsabilidade, o índice de dissimilaridade assume o valor de 0 e o $\mathrm{IOH}$ retrata apenas a taxa de cobertura.

Desta maneira, o IOH tem por finalidade mensurar a probabilidade do acesso ao conjunto de serviços básicos. Os resultados do índice variam entre 0 e 1 , sendo que $\mathrm{IOH}=1$ representa igualdade de oportunidade plena, e completa cobertura de serviços (CAVALCANTI; RAMOS, 2013).

Ademais, a formação do IOH possibilita concluir que este é Pareto-consistente, considerando que, dado o grau de ID, o aumento da cobertura de oportunidades (aumento 
na TC) amplia o valor do índice, assim como a melhoria na alocação das oportunidades existente entre os grupos (redução em ID) também o faz (FERREIRA et al., 2012).

\subsection{Análise descritiva das variáveis de circunstância e oportunidade}

Após o tratamento dos microdados da amostra do Censo do IBGE, restaram 367.083 observaçóes do ano 2000, e 324.305 do ano 2010. Dentre as variáveis de circunstância selecionadas para o presente trabalho, observa-se uma mudança na renda média per capita que em 2000 era de $\mathrm{R} \$ 458,56$ e, em 2010 passou a ser de $\mathrm{R} \$ 994,50$. A média de moradores por domicílio também sofreu modificaçôes, passando de 4,07 em 2000 para 3,75 em 2010.

Quando a distribuição de gênero e de área de residência entre os dois anos é comparada, nota-se que não ocorreram modificaçóes significativas. No entanto, o subgrupo raça/cor apresentou alteraçóes no seu arranjo, evidenciando um aumento do número de pessoas não brancas na população geral.

Após a análise descritiva da população geral, foi realizada a mesma análise para a população escolhida para ser estudada neste trabalho, sendo somente o grupo de 6 a 15 anos de idade. A partir desta seleção restaram 64.328 observaçóes para o ano de 2000 , e 51.938 para o ano de 2010. O mesmo movimento observado anteriormente no subgrupo raça/cor ocorre para este grupo, ou seja, um aumento da população não branca no grupo de 6 a 15 anos de idade. Uma pequena alteração no grupo área de residência também ocorreu, aumentando o número de moradores na regiâo urbana. A renda média per capita para este grupo da população também sofreu modificações, passando de R \$307,65 no ano de 2000 para $R \$ 609,88$ em 2010.

Para as variáveis de oportunidade, nota-se a presença de água canalizada e energia elétrica para quase $100 \%$ dos domicílios, tanto no ano de 2000 como em 2010. Houve também uma melhora no acesso à escola, saneamento básico e idade escolar adequada entre 2000 e 2010.

\subsection{Resultados para a regressão logística}

A partir da regressão logística foram obtidos os coeficientes estimados e as odds ratios para o conjunto de oportunidades proposto. Os resultados que são apresentados para a RMPA referentes ao ano de 2000 constam na Tabela 1, e para o ano de 2010 na Tabela 2.

O primeiro fato a ser salientado é que os acessos a todos os serviços básicos com coeficientes significativos evidenciaram maior probabilidade para os domicílios situados em áreas urbanas.

Em relação à variável cor/raça, esta apresentou significância para todas as oportunidades, exceto para água canalizada e para o acesso à escola em 2010. Pelos resultados, pode-se observar que os indivíduos considerados brancos apresentam maior probabilidade de acesso aos serviços básicos do que os considerados não-brancos. 
Tabela 1 - Coeficientes e odds ratios estimados pelas regressões logísticas, por tipo de oportunidade para a RMPA em 2000

\begin{tabular}{cccccc}
\hline Variável & Eletricidade & Saneamento & Água canalizada & Acesso à escola & Idade adequada \\
\hline \multirow{2}{*}{ Área } & $1,458^{*}$ & $1,879^{*}$ & $1,838^{*}$ & $0,131^{*}$ &, $179^{*}$ \\
& $(4,295)$ & $(6,548)$ & $(6,284)$ & $(1,14)$ & $(1,197)$ \\
\hline No de & $-0,126^{*}$ & $-0,054^{*}$ & $-0,071^{*}$ & $-0,073$ &,$- 129^{*}$ \\
moradores & $(0,882)$ & $(0,948)$ & $(0,932)$ & $(0,93)$ & $(0,879)$ \\
\hline \multirow{2}{*}{ Sexo } & $-0,156$ & 0,006 & $-0,106$ & $-0,054$ &,$- 175^{*}$ \\
& $(0,856)$ & $(1,006)$ & $(0,899)$ & $(0,948)$ & $(0,84)$ \\
\hline \multirow{2}{*}{ Cor/Raça } & $0,538^{*}$ & $0,194^{*}$ & $0,401^{*}$ & $0,178^{*}$ &, $396^{*}$ \\
& $(1,712)$ & $(1,214)$ & $(1,493)$ & $(1,194)$ & $(1,486)$ \\
\hline Renda per & $0,020^{*}$ & $0,004^{*}$ & $0,013^{*}$ & $0,004^{*}$ &, $000^{*}$ \\
capita & $(1,02)$ & $(1,004)$ & $(1,014)$ & $(1,004)$ & $(1,00)$ \\
\hline Constante & $2,476^{*}$ & $-0,472^{*}$ & $1,318^{*}$ & $2,629^{*}$ & $1,248^{*}$ \\
\hline
\end{tabular}

$\left({ }^{*}\right)$ valores significativos a $1 \%$. Odds ratio entre parênteses.

Fonte: Elaboração própria a partir de dados do IBGE (2015).

Tabela 2 - Coeficientes e odds ratios estimados pelas regressóes logísticas, por tipo de oportunidade para a RMPA em 2010

\begin{tabular}{|c|c|c|c|c|c|}
\hline Variável & Eletricidade & Saneamento & Água canalizada & Acesso à escola & Idade adequada \\
\hline \multirow{2}{*}{ Área } & $1,540^{*}$ & $1,593^{*}$ & $1,088^{*}$ &,- 108 &,- 087 \\
\hline & $(4,664)$ & $(4,918)$ & $(2,968)$ & $(0,897)$ & $(0,917)$ \\
\hline \multirow{2}{*}{ No de moradores } & 0,117 & $-0,093^{*}$ & $-0,098^{*}$ &,$- 120^{*}$ &,$- 067^{*}$ \\
\hline & $(1,124)$ & $(0,911)$ & $(0,907)$ & $(0,887)$ & $(0,935)$ \\
\hline \multirow{2}{*}{ Sexo } & 0,031 & $-0,035$ & $-0,111$ &, 052 &,$- 110^{*}$ \\
\hline & $(1,031)$ & $(0,966)$ & $(0,895)$ & $(1,054)$ & $(0,896)$ \\
\hline \multirow{2}{*}{ Cor/Raça } & $0,794^{*}$ & $0,174^{*}$ & 0,120 &, 140 &, $213^{*}$ \\
\hline & $(2,211)$ & $(1,19)$ & $(1,128)$ & $(1,15)$ & $(1,237)$ \\
\hline \multirow{2}{*}{ Renda per capita } & $0,005^{*}$ & $0,001^{*}$ & $0,001^{*}$ &, $001^{*}$ &, $000^{*}$ \\
\hline & $(1,005)$ & $(1,001)$ & $(1,001)$ & $(1,001)$ & $(1,00)$ \\
\hline Constante & $2,165^{*}$ & 0,143 & $3,283^{*}$ & $4,124^{*}$ & ,953* \\
\hline
\end{tabular}

$(*)$ valores significativos a $1 \%$. Odds ratio entre parênteses.

Fonte: Elaboração própria a partir de dados do IBGE (2015).

Em 2000, o número de pessoas residindo no domicílio apresentou-se estatisticamente significativo para todas as oportunidades, revelando que, quanto maior o número de indivíduos, menor é a probabilidade de acesso aos bens e serviços básicos. Em 2010, o número de pessoas residindo no domicílio não explica o acesso à eletricidade, mas é significativo para as demais oportunidades. 
Analisando a renda domiciliar per capita mensal, pode-se perceber que indivíduos com maior renda possuem maior probabilidade de acesso aos serviços básicos, visto a existência de correlaçóes positivas estatisticamente significativas entre esta variável de circunstância e as oportunidades.

O sexo dos indivíduos é apenas estatisticamente significativo para idade adequada de estudo. Contudo, a variável foi mantida para padronizar as análises.

\subsection{Resultados para o IOH}

Conforme apresentado anteriormente, o $\mathrm{IOH}$ expressa a situaçáo em que se encontram as possibilidades de acesso a determinado bem ou serviço. Portanto, o IOH permite compreender o quão distante uma sociedade está de oferecer pleno e igualitário acesso às oportunidades básicas. Um importante fato a ser destacado é que as cinco oportunidades abordadas neste trabalho foram agregadas em apenas um indicador através de média simples (FERREIRA et al., 2012). Além dos resultados gerais para o $\mathrm{IOH}$ da RMPA, também serão apresentados os resultados para cada uma das oportunidades em análise.

Em 2010 a RMPA obteve uma pequena queda em seu resultado agregado do $\mathrm{IOH}$ quando se compara com o resultado de 2000. Este movimento pode ser identificado por meio do Gráfico 1, em que se observa o aumento da desigualdade no acesso ao saneamento básico, mas principalmente estar em idade adequada de estudo.

Gráfico 1 - Evolução do IOH agregado para RMPA em 2000 e 2010

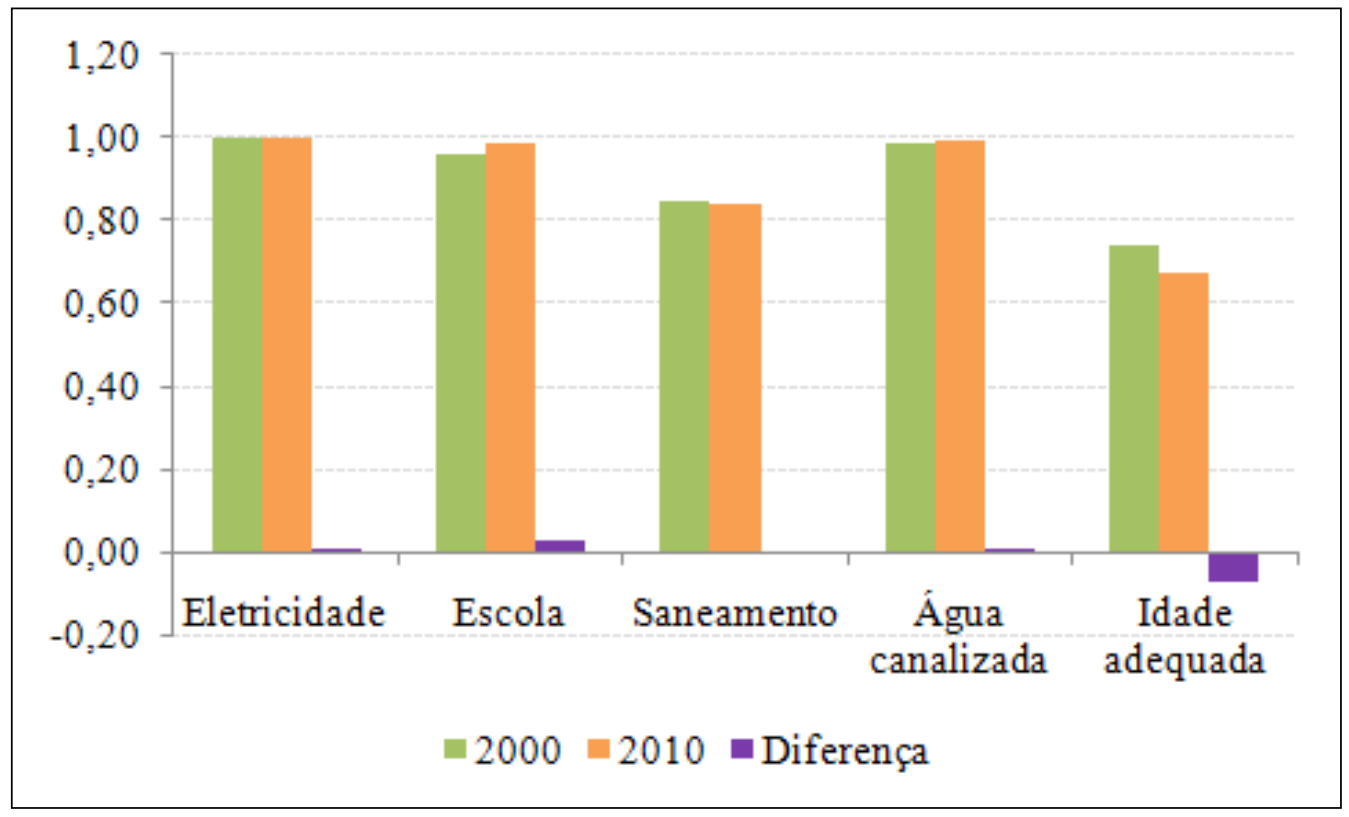

Fonte: Elaboração própria. 
Mesmo havendo avanços no acesso à eletricidade, escola e água canalizada no último ano, os resultados náo foram suficientes para aumentar o IOH geral da RMPA. A queda dos números da idade escolar adequada pode ser atribuída a todos os municípios da regiáo, exceto Glorinha, pois foi o único que apresentou melhora nesta dimensão. Por meio do Gráfico 2 é possível observar a diminuição do indicador da idade escolar adequada ao longo dos 10 anos.

Em relação ao acesso à escola, Alvorada em 2000 apresentava o pior desempenho no acesso à escola, e mesmo havendo um aumento expressivo deste aspecto no último ano, percebe-se que o município permanece nas últimas colocaçóes (Gráfico 3). Ao analisar o comportamento deste município em relação ao acesso à escola e estar em idade adequada de estudo, os dois indicadores apresentam baixos resultados, demonstrando a necessidade de melhorias na esfera educacional. No entanto, os municípios de Ivotí e Charqueadas apresentam $100 \%$ de acesso a este serviço em 2010, indicando que mais crianças estão estudando.

Gráfico 2 - Resultados do IOH para variável idade escolar adequada nos municípios da RMPA para os anos de 2000 e 2010

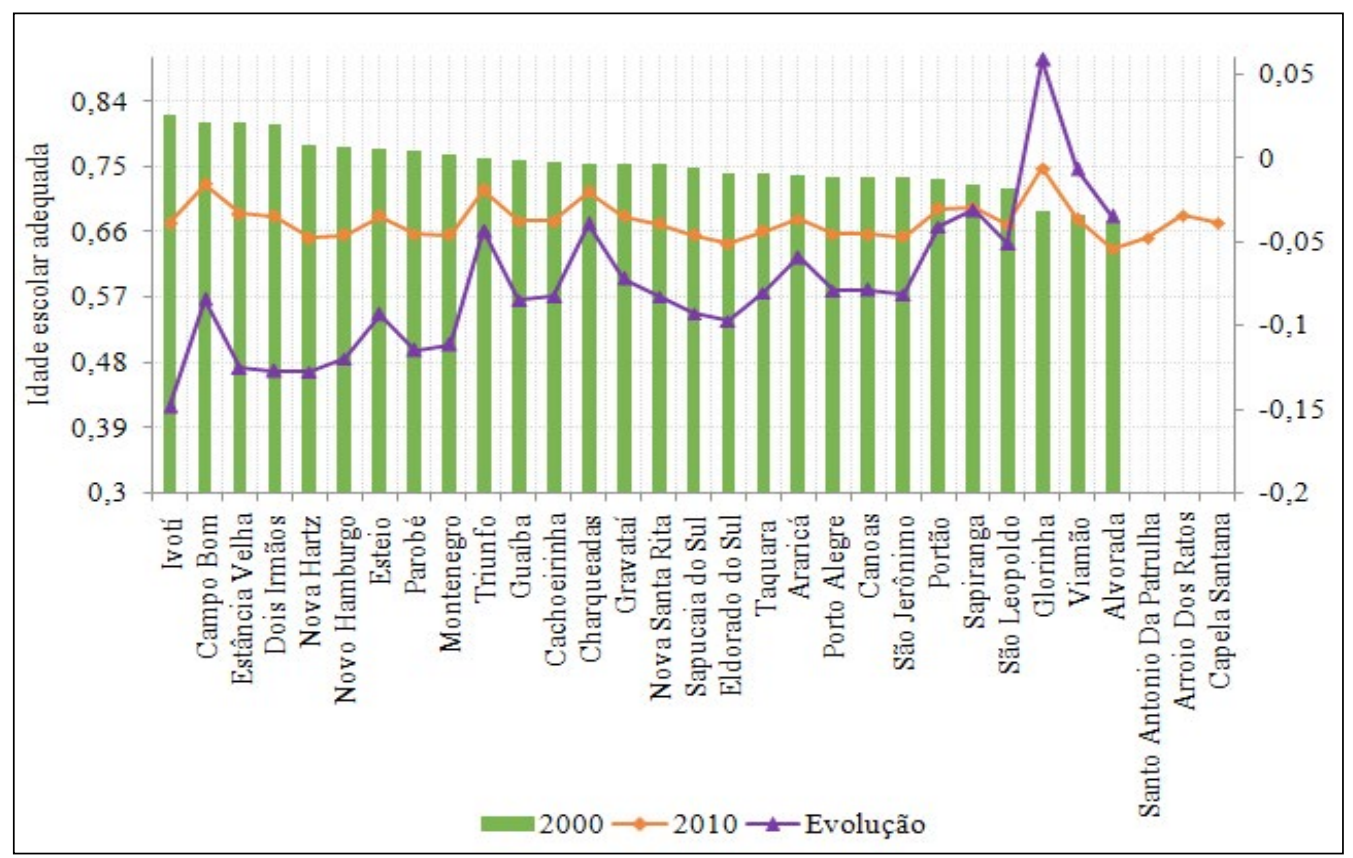

Fonte: Elaboração própria.

Em relação ao $\mathrm{IOH}$ para a variável eletricidade, sete municípios conseguiram atingir o valor 1 nesta dimensão no ano de 2000, demonstrando desta maneira a universalização no acesso a este serviço. $\mathrm{O}$ mesmo ocorreu em 2010 para nove municípios, porém somente Charqueadas e Dois Irmãos conseguiram apresentar este efeito nos dois anos. São Jerônimo, que foi o município com o pior resultado em 2000 , apresentou $100 \%$ de acesso a este serviço em 2010, evidenciando assim grandes melhorias em termos de cobertura desse serviço. 
Gráfico 3 - Resultados do IOH para variável acesso à escola nos municípios da RMPA para os anos de 2000 e 2010

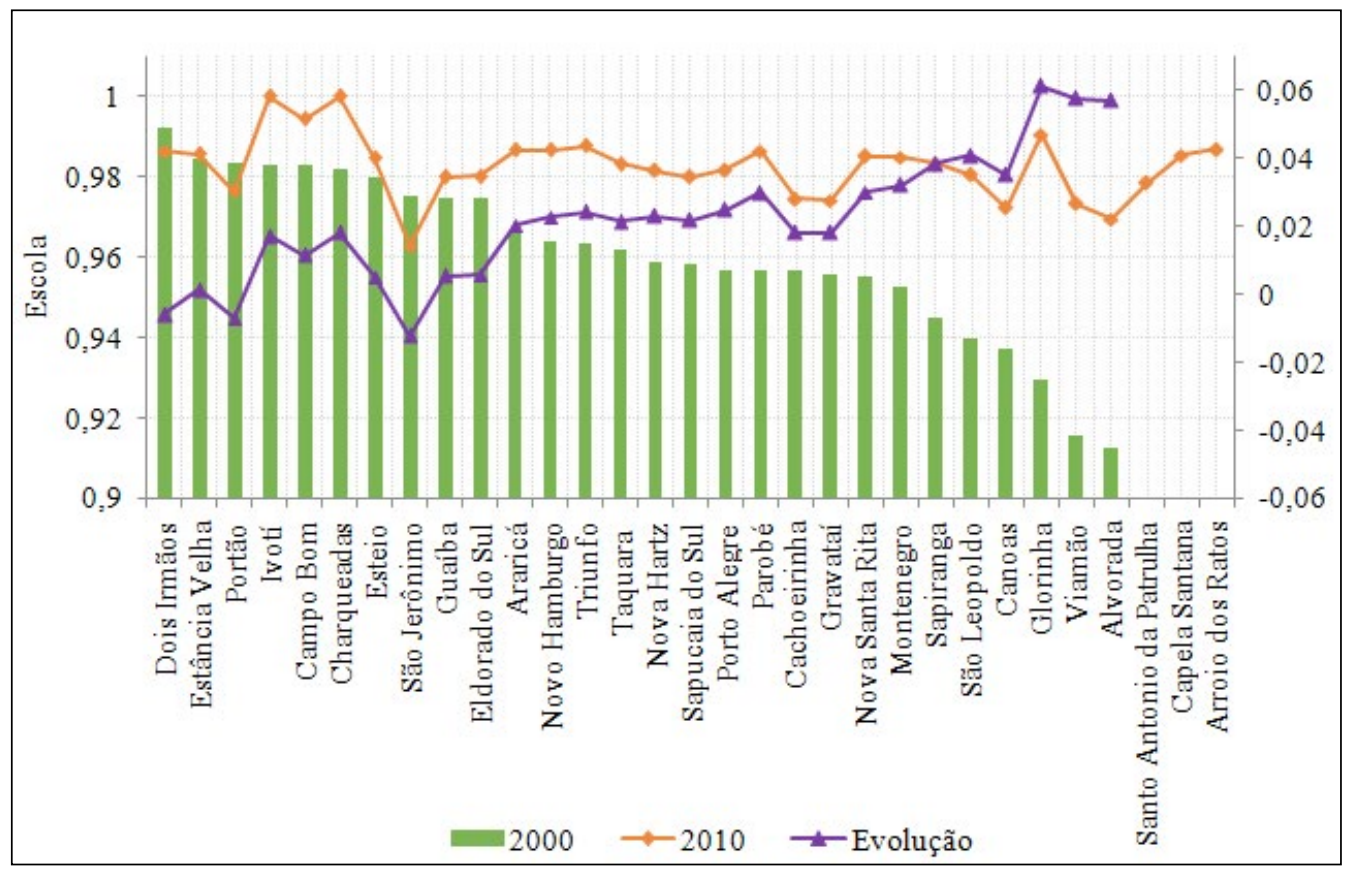

Fonte: Elaboração própria.

Para a variável de acesso à água canalizada, em 2000 o melhor resultado era do município de Dois Irmãos, e o pior, de Triunfo. Foi possível observar avanços nesta dimensão no último ano para os municípios de Ivotí, Charqueadas e Dois Irmãos, pois estes apresentaram $100 \%$ de acesso neste serviço, demonstrando aumento da taxa de cobertura para água canalizada.

Ao analisar o Gráfico 4, o qual ilustra o IOH para o acesso ao saneamento adequado, nota-se a alta disparidade de resultado entre os municípios, mas principalmente quando se observam Dois Irmãos e Triunfo. No caso do município de Triunfo, esse movimento ocorre em razão da baixa taxa de cobertura, o que influencia de maneira negativa o índice. Nota-se que há melhoras no acesso a este serviço para metade dos municípios, no entanto, há poucas alteraçóes no desempenho entre os maiores e menores números deste indicador.

A partir do Gráfico 5, é possível observar que Triunfo, Glorinha, Portão, Viamão, Charqueadas, São Leopoldo, Eldorado do Sul, Nova Hartz e Sapiranga foram os únicos municípios que superaram os resultados do ano de 2000 no IOH, revelando um acréscimo na taxa de cobertura dos serviços públicos. Nota-se uma queda nos números do índice quando comparados os resultados do ano de $2010 \mathrm{em}$ relação ao ano de 2000. Isto pode ser constatado pois em 2000 o melhor resultado era do município de Dois Irmáos, o qual apresentava IOH de 0,9537 . No entanto, em 2010 o melhor resultado passou a ser de Charqueadas, apresentando 0,9258 para o índice. 
Gráfico 4 - Resultados do $\mathrm{IOH}$ para variável acesso ao saneamento adequado nos municípios da RMPA para os anos de 2000 e 2010

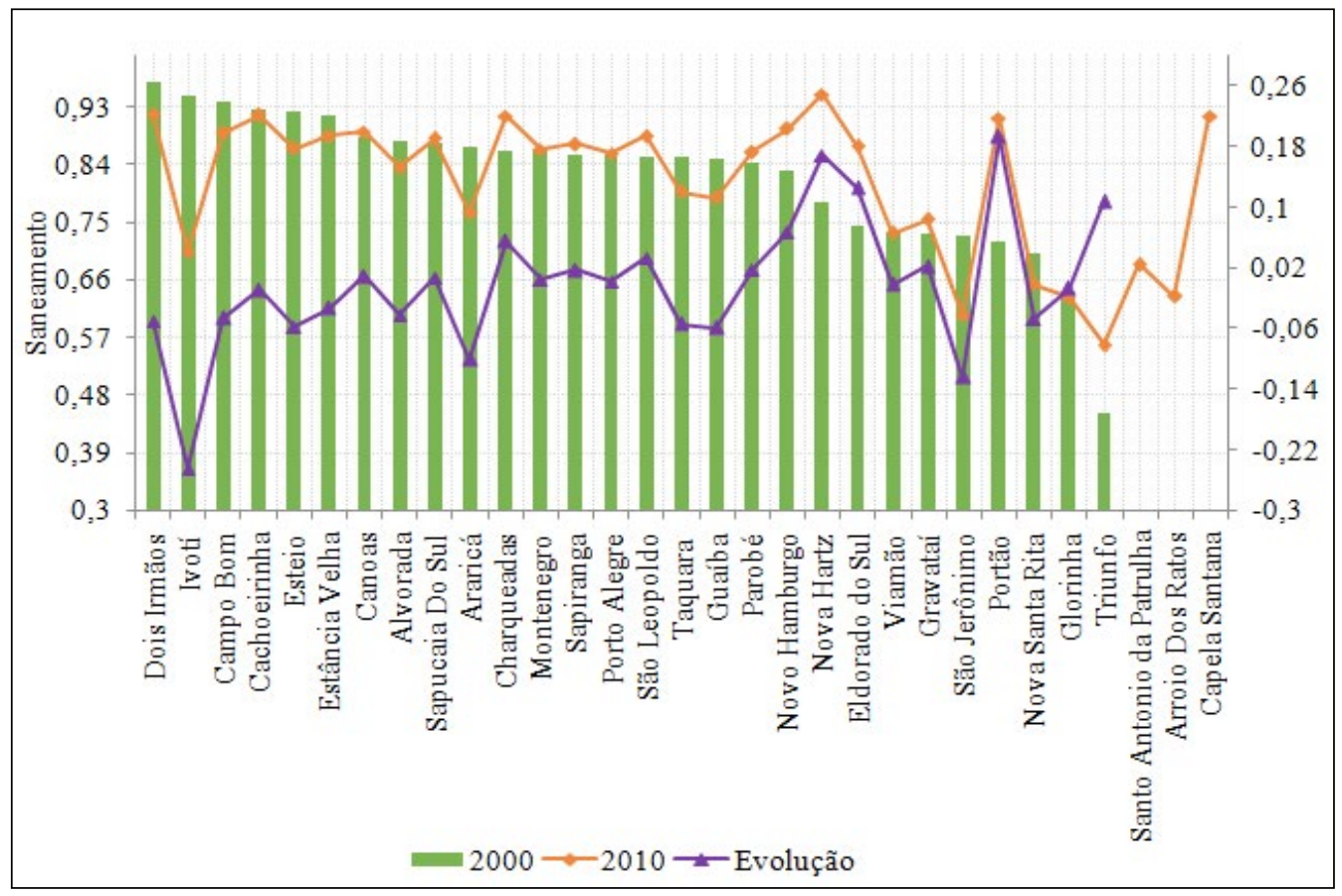

Fonte: Elaboração própria.

Vale destacar que Charqueadas obteve o melhor desempenho dentre os municípios analisados, pois ocupava a sétima colocação do índice em 2000 e no último ano passou a ser o município com maior IOH da RMPA. Isso ocorreu porque este município apresentou $100 \%$ de acesso a eletricidade, escola e água canalizada no último ano.

Os resultados observados para $\mathrm{IOH}$ ocasionaram certas vezes o descolamento das curvas entre um ano e outro para alguns municípios. Mesmo havendo melhora nos indicadores para alguns municípios, o que se almeja é que sempre haja aumento dos resultados para todos que compóem a RMPA, e que em um futuro todos tenham acesso pleno e igualitário a estes bens e serviços básicos. 
Gráfico 5 - Resultados do IOH para os municípios da RMPA nos anos de 2000 e 2010

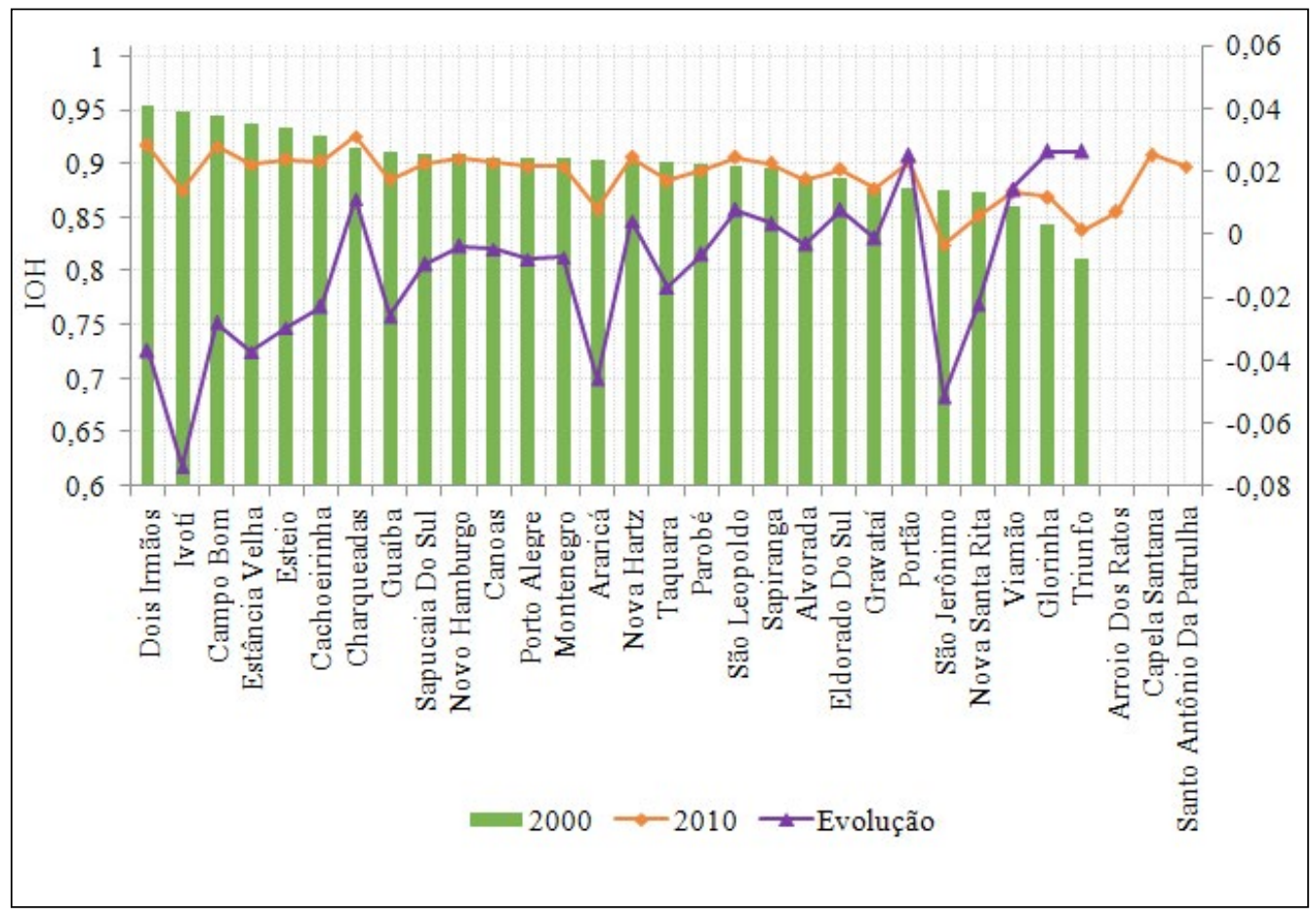

Fonte: Elaboração própria.

\section{CONSIDERAÇÓES FINAIS}

Este trabalho se propôs a contribuir com os estudos sobre as desigualdades de oportunidade, buscando mensurar a distribuiçáo do acesso aos serviços básicos entre os municípios da RMPA. Em conformidade com as definiçôes de Barros (2009), foi construído o IOH para os anos de 2000 e 2010.

No decorrer deste trabalho observou-se que o Brasil traz consigo a desigualdade de renda como problemática em seu histórico, mas vem apresentando grandes melhorias nos últimos anos. Diante deste cenário, buscou-se apresentar as abordagens em torno das oportunidades humanas, pois conforme Roemer (1998) destaca, a desigualdade de renda é decorrência da interação entre as circunstâncias e o esforço dos indivíduos.

Conforme já destacado, notou-se a necessidade de realizaçáo deste estudo para a RMPA devido ao seu importante espaço na economia gaúcha. E, ao longo deste trabalho, foi possível identificar as mudanças ocorridas nesta regiáo ao longo do tempo desde a sua formação.

A partir da regressão logística, foi possível perceber que as circunstâncias apresentaram maior probabilidade de acesso às oportunidades para os indivíduos de cor branca, residentes da área urbana, com poucos moradores no domicílio, e com renda per capita maior. $\mathrm{O}$ sexo não se mostrou significativo para o acesso às oportunidades. 
Os resultados encontrados no $\mathrm{IOH}$ agregado apontam para uma pequena piora da RMPA no período analisado. Esta queda deve-se à diminuição na disponibilidade do serviço de saneamento básico e da idade escolar adequada, assim como o aumento na desigualdade no acesso a estes serviços.

Ao analisar o acesso a cada uma das cinco oportunidades, percebeu-se que a eletricidade e a água canalizada são praticamente universais nesta região. Foi possível observar que ocorreu ampliação nestas duas dimensóes, mas o acesso à escola foi a oportunidade que apresentou melhor resultado no último ano. A idade escolar adequada e o saneamento básico foram as dimensóes com pior desempenho, apresentando espaço para grandes melhorias na distribuição do acesso, de tal forma que haja diminuição da desigualdade.

Percebeu-se a existência de desigualdade de oportunidade entre os municípios da RMPA em 2010, mas principalmente no acesso ao saneamento, em que se observa o município de Nova Hartz com índice de 0.9498, ao passo que Triunfo apresenta 0.5575.

Em suma, o trabalho possibilitou compreender a necessidade de políticas públicas focalizadas na melhoria do acesso aos serviços básicos, principalmente nos municípios de Sáo Jerônimo e Triunfo, pois apresentaram pior resultado para o $\mathrm{IOH}$ geral e nas dimensóes analisadas individualmente.

Como limitação do presente estudo, tem-se a insuficiência de dados no Censo 2000 e 2010, fazendo com que o presente trabalho não pudesse considerar circunstâncias como: a presença da mãe no domicílio e do nível de escolaridade da pessoa de referência da família. Além disso, a metodologia escolhida permite, apenas calcular a cobertura e distribuição das oportunidades básicas de acordo com as circunstâncias. Não sendo possível, a partir deste indicador extrair conclusóes mais elaboradas ou mesmo identificar efeitos diretos e indiretos das circunstâncias nas oportunidades e nos níveis de esforço.

Sugere-se que futuros trabalhos busquem ampliar o conjunto de variáveis de circunstância na construção do $\mathrm{IOH}$, podendo também adicionar outros serviços básicos, como saúde, para a constituição das oportunidades. Adicionalmente, podem ser adotados métodos mais completos de análise da desigualdade de oportunidades.

\section{REFERÊNCIAS}

ALONSO, J. A F.; BRINCO, J. Caracterizaçáo geral da Regiáo Metropolitana de

Porto Alegre (RMPA). 2009. Disponível em: <http://cdn.fee.tche.br/metropole/01.pdf>. Acesso em: 15 de ago. de 2015.

BARROS, R. P.; FERREIRA, F. H. G.; VEGA, J. M.; CHANDUVI, J. S. Medida da desigualdade de oportunidades na América Latina e no Caribe. Washington; São Paulo: Banco Mundial; Singular, 2009.

BARCELOS, T. M. M.; JARDIM, M. L. T. Porto Alegre: Transformaçóes na Ordem Urban a. Rio de Janeiro: Letra Capital, 2015. 
BOURGUIGNON, F.; FERREIRA, F. H. G.; MENÉNDEZ, M. Inequality of Opportunity in Brazil. Review of Income and Wealth, Series 53, no 4, p. 585-618, Dez. 2007.

CAVALCANTI, D. M.; RAMOS, F. S. Igualdade de oportunidade nas regiōes brasileiras: um estudo de sua evolução e composição, no período de 2002 a 2012. In: ENCONTRO REGIONAL DE ECONOMIA, 19, 2013. Anais... Encontro Regional de Economia. Banco do Nordeste, 2013. Disponível em: <http://www.bnb.gov.br/artigos-do-xixencontro-regional>. Acesso em: 10 de set. de 2015

CATALÃO, I. Entre a institucionalização e a vida quotidiana: elementos para repensar o espaço metropolitano de Brasília. São Paulo: v.11, n. 22, p. 519-544, jul.-dez. 2009. Disponível em: <http://revistas.pucsp.br/index.php/metropole/article/view/5946/4299>. Acesso em: 11 de mai. de 2015.

Fundação de Economia e Estatística. FEE. FEEDADOS. Disponível em: <http://www. fee.rs.gov.br>. Acesso em: 10 set. 2015.

FERREIRA, D.; GONÇALVES, F.O.; OLIVEIRA, V. R. Igualdade de oportunidades: Uma análise espacial para os municípios brasileiros a partir do Censo 2010. 2012. Disponível em: <http://www.anpec.org.br/encontro/2012/inscricao/files_I/i9-63cd1af0d7 eba2ccb43c0d1382c9c9aa.pdf>. Acesso em: 13 de mai. de 2015.

FIGUEIREDO, E. A.; SILVA, C. R. F.; REGO, H. O. Desigualdade de Oportunidades no Brasil: Efeitos diretos e indiretos. Economia Aplicada, v. 16, n. 2, p. 237-254, 2012. Disponível em: < http://www.scielo.br/pdf/ecoa/v16n2/v16n2a02.pdf>. Acesso em: 5 de jul. de 2015.

FILHO, J. J.; MIRO, V.; SULIANO, D. Avaliando as condiçóes de oportunidade a partir do IOH ao longo da década de 2000: Evidências para o Ceará. RPD - Revista Paranaense de Desenvolvimento, v. 35, n. 127, 2014. Disponível em: http://www.ipece. ce.gov.br/publicacoes/textos_discussao/TD_104.pdf. Acesso em: 13 de abr. de 2015.

Instituto Brasileiro e Geografia e Estatística. IBGE. Disponível em: <http://www.ibge.gov. br>. Acesso em: 10 set. 2015.

MARTINS, C. M. R. Caracterizaçáo da Regiáo Metropolitana de Porto Alegre. Porto Alegre: FEE, 2013. (Texto para Discussão, 112). Disponível em: <http://cdn.fee.tche.br/ tds/112.pdf>. Acesso em: 20 de mai. de 2015.

PAES DE BARROS, R. FOGUEL, M. N. ULYSSEA, G. Desigualdade de Renda no Brasil: uma análise da queda recente. Brasília: Ipea, 2006. 2 v.

RAWLS, J. A Theory of Justice. Cambridge, MA: Harvard University Press, 1971. 
ROEMER, J.E. Equality of opportunity. Cambridge, M.A: Harvard University Press, 1998.

SEN, A. Desenvolvimento como liberdade. São Paulo: Companhia de bolso, 2000.

SOUZA, R. M. Crescimento econômico e desigualdade na distribuiçáo de renda no Brasil dos anos 1970 a 2007. 2009. 56f. Trabalho de Conclusão de Curso (Graduação) - Curso de Ciências Econômicas da Universidade Federal do Rio Grande do Sul, Porto Alegre. Disponível em: < http://www.lume.ufrgs.br/handle/10183/25369>. Acesso em: 11 de out. de 2015. 